\title{
Analysis of soil radon data in earthquake precursory studies
}

\author{
Hari Prasad Jaishi ${ }^{1}$, Sanjay Singh ${ }^{1}$, Raghavendra Prasad Tiwari ${ }^{2}$, Ramesh Chandra Tiwari ${ }^{1, \star}$ \\ ${ }^{1}$ Mizoram University, Department of Physics, Aizawl, India \\ ${ }^{2}$ Mizoram University, Department of Geology, Aizawl, India
}

\author{
Article history \\ Received February 19, 2014; accepted September 15, 2014. \\ Subject classification: \\ Surveys, measurements and monitoring, Geochemical data, Statistical analysis.
}

\section{ABSTRACT}

Soil radon data were recorded at two selected sites along Mat fault in Mizoram (India), which lies in the highest seismic zone in India. The study was carried out during July 2011 to May 2013 using LR-115 Type II films. Precursory changes in radon concentration were observed prior to some earthquakes that occurred around the measuring sites. Positive correlation was found between the measured radon data and the seismic activity in the region. Statistical analysis of the radon data together with the meteorological parameters was done using Multiple Regression Method. Results obtained show that the method employed was useful for removing the effect of meteorological parameters and to identify radon maxima possibly caused by seismic activity.

\section{Introduction}

Variation of radon concentration in soil can give evidence on tectonic disturbances in the Earth's crust [King 1986]. However, the changes in radon concentration are not only controlled by seismic activity but also influenced by meteorological parameters like soil moisture, rainfall, temperature, barometric pressure and relative humidity [Kraner et al. 1964, Pearson 1967, Singh et al. 1988, King and Minissale 1994, Virk et al. 2000, Zmazek et al. 2003, Walia et al. 2005]. These parameters change the physical characteristics of the soil and thus affect the soil radon variation caused by geophysical processes. Therefore, theoretical and empirical algorithm is necessary for removing the effects of meteorological parameters [Zmazek et al. 2003, Ramola et al. 2008, Choubey et al. 2009].

Northeast India is seismically one of the six most active regions of the world, the other five being Mexico, Taiwan, California, Japan and Turkey. It lies at the junction of Himalayan arc to the north and Burmese arc to the east [Jaishi et al. 2014a, Singh et al. 2014]. The high seismicity in this zone is due to the collision tectonics between the Indian plate and the Eurasian plate in the north and Subduction tectonics along the Indo-Myanmar Range (IMR) in the east [Dewey and Bird 1970]. Based on the distribution of epicentres, fault plane solutions and geotectonic features, northeast region can be divided into five seismotectonic zones which include Eastern Himalayan collision zone, Indo-Myanmar subduction zone, Syntaxis zone of Himalayan arc and Burmese arc (Mishmi Hills), Plate boundary zone of the Shillong plateau and Assam valley, and Bengal basin and plate boundary zone of Tripura- Mizoram fold belt (Figure 1). The Indo- Myanmar subduction zone is highly seismic zone extending from the Bay of Bengal to the Mishmi

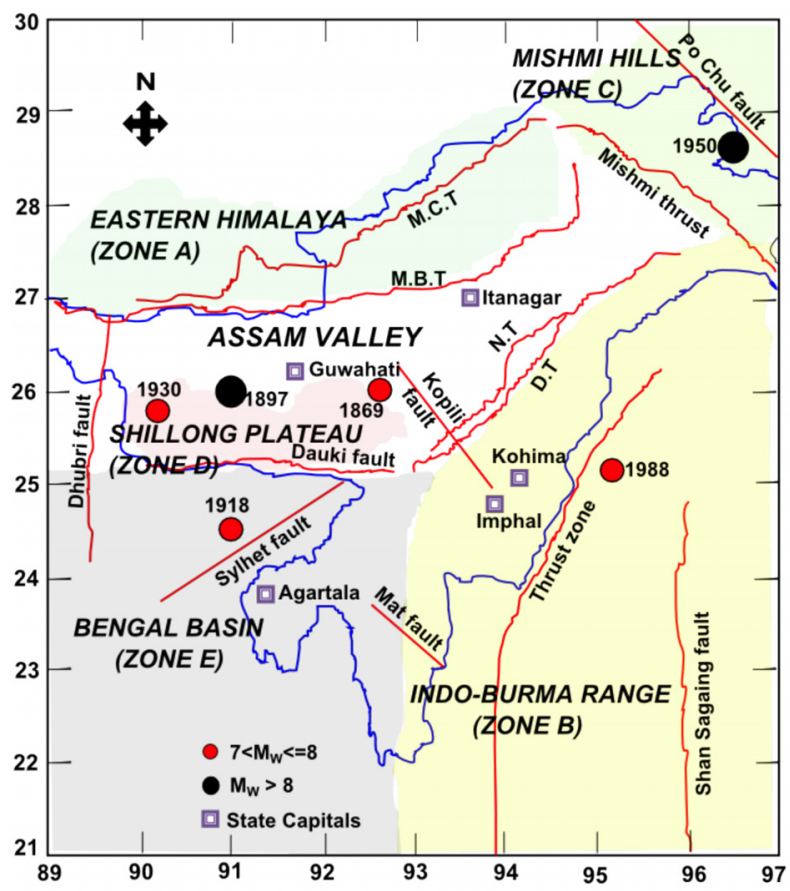

Figure 1. Seismo-tectonic map of North East India showing epicentres of damaging earthquakes (modified after Raghukant and Dash [2009]). Tectonic zones (zones A, B, C, D and E) and major thrusts (MBT-Main Boundary Thrust; MCT-Main Central Thrust; NT-Naga Thrust; DT-Disang Thrust) are also shown. Thick blue line represents the International boundary of North Eastern part of India bordering Myanmar and Bangladesh (not to scale) and red lines represents faults and thrusts. 
block in a N-S, NNE-SSW and NE-SW directions. The main discontinuities in this zone are Naga thrust and the Disang thrust. The seismic activity in the Bengal basin may be related to an intra plate activity whereas Tripura- Mizoram fold belt to plate- boundary activity. The main tectonics domains in this region are E-W trending Dauki fault, N-E trending Sylhet fault, NE-SW Hail- Hakula lineament, NNW Tista fault, Mat fault and Tuipui fault. Mat fault is the most prominent fault in Mizoram state [Jaishi et al. 2014b]. It obliquely cuts across the general north-south trend of the Indo-Burmese arc. It trends NW-SE (Figure 2) and is traceable across entire Mizoram on the satellite as well as on the geological maps. Mat River crosses the Mat fault and follows it for considerable distance. Most pronounced part of this fault is in Serchhip district along Serchhip-Thenzawl road. Hence this part has been selected for monitoring of radon anomaly and their possible correlation with the occurrence of earthquakes. Authors have done primary analysis of soil radon and thoron anomalies as a precursor to earthquakes [Jaishi et al. 2013, 2014a, 2014b, Singh et al. 2014]. The present paper describes the multiple regression method to differentiate those radon anomalies which are solely caused by seismic events and not by meteorological parameters.

\section{Materials and methods}

For radon monitoring in soil, we have used LR115(II) cellulose nitrate detector manufactured by Kodak Pathe in France, a useful solid state nuclear track detector (SSNTD) for registering the alpha tracks generating from radon gas. The LR-115 (II) films of size $3 \mathrm{~cm} \times 3 \mathrm{~cm}$ was attached in the dosimeter with the sen-

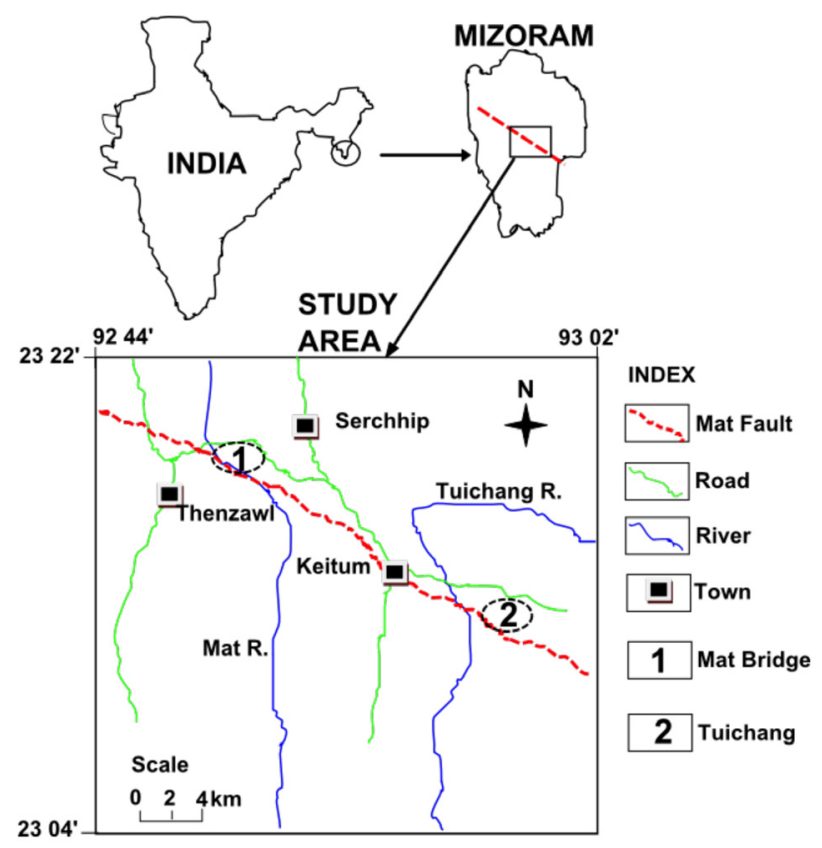

Figure 2. Location map of study area. sitive side facing downwards for exposure. The dosimeter has been developed at the Bhabha Atomic Research Centre (BARC), India. The dosimeters were buried in holes of depth of about $80 \mathrm{~cm}$ in the soil (Figure 3). The detector films were exposed for a period of 15 days, after that the exposed films were removed and reinstalled with the new one in the dosimeters. The SSNTD's are etched with $10 \%$ sodium hydroxide solution in an etching bath at a temperature of $60^{\circ} \mathrm{C}$ for developing the registered tracks. The etching time was set for 1 hour. The track etched method removes a bulk thickness of $4 \mu \mathrm{m}$ leaving a residual thickness of $8 \mu \mathrm{m}$. As soon as the etching process is complete, films were washed in cold running water and then kept in distilled water for two hours. The detector films are pre-sparked at a voltage of $900 \mathrm{~V}$ to fully develop the partially etched track holes using spark counter. The tracks are then counted at a voltage corresponding to plateau region of the counter (around 450V).

\section{Results and discussion}

Radon concentration in soil gas have been measured after every 15 days using LR-115(II) films during July 2011 to May 2013 together with the meteorological parameters viz.; rainfall, relative humidity, air temperature and barometric pressure at two locations (Mat Bridge and Tuichang) in Serchhip District, Mizoram (India). Numerous criteria have been used by different authors [Rannou 1990, Price et al. 1994, King et al. 1996, Fu et al. 2005] in order to calculate soil radon gas anomalies which include mean plus ' $n$ ' (where $n=1,2,3, \ldots$ ) standard deviation (SD). Fleischer [1981] proposed the empirical relation between the magnitude $(\mathrm{M})$ of the

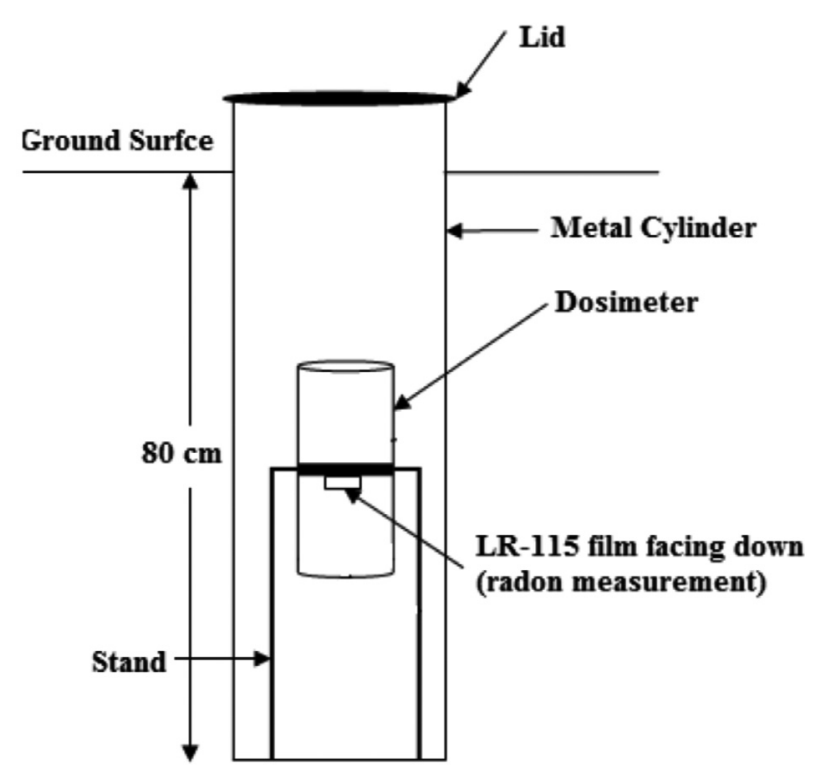

Figure 3. Schematic description of the equipment used for radon measurements in soil. 
earthquake and the epicentre distance (D) within which the earthquake prediction zone can be manifested.

$$
D=\frac{10 \exp 0.48 M}{1.66} \mathrm{~km}
$$

The details of the earthquakes (www.imd.gov.in) that occurred around the study areas fulfilling Equation (1) is summarised in Table 1.

\section{Multiple Linear Regression (MLR) Model}

Multiple regression analysis permits the study of several independent (predictor) variables for a given dependent (criterion) variable. For ' $n$ ' predictor variables the raw score regression equation is given by

$$
Y^{\prime}=a+b_{1} X_{1}+b_{2} X_{2}+\ldots+b_{n} X_{n}
$$

where, $Y^{\prime}$ is the predicted value of the dependent variable, $a$ is the constant term and $b_{1}, b_{2}, \ldots, b_{n}$ represents the regression coefficient of the independent variables $X_{1}, X_{2}, \ldots, X_{n}$ respectively. The drawback of the raw score regression is that the size of the $b$-coefficients is dependent on the scale of the predictor variables. Therefore, they cannot be compared directly with each other to determine which predictor variable has the most influence on the criterion. By standardizing both the coefficients and the variables we could make direct comparison among the coefficients [Yount 2006]. The standardized regression equation takes the form

$$
Z_{Y}^{\prime}=\beta_{1} Z_{X 1}+\beta_{2} Z_{X 2}+\ldots+\beta_{n} Z_{X n}
$$

where, $\beta$ 's represents the standardized coefficients and $Z$ 's represents the Z-scores. In the present investigation we perform MLR taking soil radon concentration $(R n)$ as the dependent variable and the meteorological parameters viz. Rainfall $(R F)$, relative humidity $(R H)$, temperature $(T)$ and pressure $(P)$ as independent variables. The data used for analysis is reported in Table 2.

\section{Data analysis at Mat Bridge}

At Mat Bridge $R n_{1}$ is regressed with $R F, R H, T$ and $P$ (taken from Table 2 ). All the predictor variables mentioned may not be a significant predictor of the dependent variable. To deal with this problem and to build a better model we perform backward regression method using SPSS statistical package. The backward regression method starts with all the predictor variables, test the significance of each predictor variable using a t-test and then delete the variable (if any) that improves the model the most by being deleted. This process is repeated until the maximum number of steps is reached or no more independent variable qualifies for removal [Hocking 1976]. Table 3 shows the coefficients of the backward regression output. The backward regression output of the data has four distinct models (Model 1, Model 2, Model 3 and Model 4). The first model includes all the predictor variables $(R F, R H, T$ and $P$ ). To check the significance of the predictor variables a t-test is performed at $95 \%$ confidence interval (i.e., the alpha value is set at 0.05 ) and its corresponding probability is shown in sig. column of the table (see Table 3). If we look at the significance of each predictor variable in Model 1, two predictor variables ( $T$ and $P)$ are non-significant predictors of the dependent variable as the p-value (sig.) is more than $\alpha$-value (0.05) in both the cases. The backward regression method eliminates one predictor variable at a time (the predictor variable with the highest $\mathrm{p}$-value is deleted first). So, temperature $(T)$ having the highest p-value (0.757) is removed from Model 1 and a second model is constructed with $R F, R H$ and $P$ as independent variables. In Model 2, $P$ is a non significant predictor (since the $\mathrm{p}$ value is more than 0.05 ). Therefore, $P$ is removed from the model and a third model is built with $R F$ and $R H$ as predictor variables. Model 3 tells us that $R F$ is a non significant predictor (since the $\mathrm{p}$-value is much more than

\begin{tabular}{|c|c|c|c|c|}
\hline \multirow{2}{*}{$\begin{array}{c}\begin{array}{c}\text { Day of } \\
\text { occurrence }\end{array} \\
65 \text { th day }\end{array}$} & \multirow{2}{*}{$\begin{array}{l}\text { Magnitude } \\
\qquad(\mathrm{M}) \\
6.8\end{array}$} & \multicolumn{2}{|c|}{$\begin{array}{l}\text { Distance of epicentre }(\mathrm{km}) \\
\text { from Mat Bridge and Tuichang }\end{array}$} & \multirow{2}{*}{$\begin{array}{c}\begin{array}{c}\text { Region of } \\
\text { occurrence }\end{array} \\
\text { Sikkim-Nepal Border region }\end{array}$} \\
\hline & & 673 & 689 & \\
\hline 129th day & 5.8 & 323 & 320 & India-Myanmar Border region \\
\hline 353rd day & 5.8 & 323 & 324 & Phek (Nagaland), India \\
\hline 381st day & 6.0 & 147 & 132 & Myanmar \\
\hline 486th day & 6.7 & 327 & 304 & Myanmar \\
\hline 545th day & 5.9 & 314 & 312 & India-Myanmar Border region \\
\hline 597th day & 5.2 & 174 & 187 & India-Bangladesh Border region \\
\hline
\end{tabular}
$0.05) . R F$ is therefore removed from the model and a fourth model is built with $R H$ as a single predictor vari-

Table 1. Details of earthquakes that occurred around the study area during the period of investigation (earthquake data obtained from: www.imd.gov.in). 
JAISHI ET AL.

\begin{tabular}{|c|c|c|c|c|c|c|}
\hline Days & $\begin{array}{l}\text { Radon conc. } \\
\text { at Mat Bridge } \\
R n_{1}\left(\text { Tr. } \mathrm{cm}^{-2}\right)\end{array}$ & $\begin{array}{l}\text { Radon conc. } \\
\text { at Tuichang } \\
R n_{2}\left(\operatorname{Tr} . \mathrm{cm}^{-2}\right)\end{array}$ & $\begin{array}{c}R F \\
(\mathrm{~mm})\end{array}$ & $\begin{array}{l}\text { RH } \\
(\%)\end{array}$ & $\begin{array}{c}\mathrm{T} \\
\left({ }^{\circ} \mathrm{C}\right)\end{array}$ & $\begin{array}{c}P \\
\text { (mbar) }\end{array}$ \\
\hline 15 & 814 & 687 & 131.7 & 92.4 & 23.93 & 888.29 \\
\hline 30 & 528 & 476 & 184 & 93.7 & 23.8 & 888.38 \\
\hline 45 & 682 & 305 & 258.5 & 92.7 & 23.9 & 890.78 \\
\hline 60 & 242 & 215 & 172 & 91.8 & 24.37 & 889.91 \\
\hline 75 & 342 & 123 & 138 & 90.5 & 23.66 & 890.83 \\
\hline 90 & 413 & 441 & 58.6 & 85.6 & 24.46 & 893.56 \\
\hline 105 & 126 & 75 & 23.8 & 80.4 & 22.42 & 894.69 \\
\hline 120 & 129 & 72 & 0 & 70 & 21.16 & 895.81 \\
\hline 135 & 143 & 88 & 0 & 69.5 & 21.12 & 896.44 \\
\hline 150 & 154 & 170 & 0 & 72.6 & 19.01 & 895.73 \\
\hline 165 & 93 & 74 & 0 & 63.5 & 19.11 & 896.01 \\
\hline 180 & 153 & 204 & 20.3 & 80.6 & 16.49 & 896.81 \\
\hline 195 & 69 & 76 & 0 & 69.2 & 16.85 & 894.5 \\
\hline 210 & 130 & 102 & 0 & 62.6 & 19.31 & 895.81 \\
\hline 225 & 65 & 55 & 7.3 & 61.8 & 21.1 & 892.67 \\
\hline 240 & 91 & 55 & 46.9 & 69.6 & 21.15 & 892.68 \\
\hline 255 & 97 & 67 & 0 & 61.4 & 24.45 & 894.36 \\
\hline 270 & 107 & 81 & 112.3 & 74.9 & 22.09 & 894.28 \\
\hline 285 & 41 & 11 & 152.4 & 87 & 22.33 & 891.61 \\
\hline 300 & 104 & 48 & 118.8 & 81.8 & 23.07 & 891.49 \\
\hline 315 & 339 & 126 & 56.8 & 86.5 & 24.81 & 889.16 \\
\hline 330 & 590 & 90 & 211.1 & 91.3 & 23.67 & 887.36 \\
\hline 345 & 121 & 84 & 262.9 & 93.4 & 22.79 & 886.05 \\
\hline 360 & 145 & 504 & 158.8 & 90.6 & 23.93 & 887.07 \\
\hline 375 & 666 & 215 & 93.6 & 92.7 & 23.45 & 887.09 \\
\hline 390 & 286 & 192 & 265.5 & 93.13 & 24.23 & 887.63 \\
\hline 405 & 148 & 67 & 200.4 & 93.12 & 23.49 & 889.84 \\
\hline 420 & 241 & 190 & 203.7 & 92.1 & 23.53 & 891 \\
\hline 435 & 562 & 185 & 160.2 & 91 & 23.57 & 893.07 \\
\hline 450 & 214 & 208 & 171.1 & 89.1 & 21.84 & 894.45 \\
\hline 465 & 260 & 419 & 0 & 85.5 & 22.25 & 896.27 \\
\hline 480 & 256 & 304 & 109.9 & 88.2 & 19.68 & 895.98 \\
\hline 495 & 325 & 384 & 6.1 & 84.4 & 19.87 & 895.84 \\
\hline 510 & 180 & 171 & 0 & 77.2 & 18.37 & 896.53 \\
\hline 525 & 319 & 328 & 0 & 65.7 & 17.74 & 895.3 \\
\hline 540 & 448 & 447 & 0 & 69.8 & 15.39 & 895.77 \\
\hline 555 & 198 & 204 & 0 & 70.5 & 18.02 & 896.14 \\
\hline 570 & 186 & 235 & 0 & 69 & 21.03 & 895.66 \\
\hline 585 & 162 & 205 & 3.3 & 66 & 21.38 & 894.42 \\
\hline 600 & 158 & 157 & 0 & 63.6 & 23.68 & 894.99 \\
\hline 615 & 377 & 335 & 5.6 & 73.3 & 23.76 & 893.35 \\
\hline 630 & 415 & 371 & 21.5 & 74.3 & 25.19 & 891.81 \\
\hline 645 & 99 & 80 & 39.9 & 80.2 & 22.54 & 892.69 \\
\hline 660 & 101 & 95 & 324.4 & 93.6 & 20.2 & 890.18 \\
\hline 675 & 378 & 307 & 124 & 87.7 & 23.43 & 888.58 \\
\hline
\end{tabular}

Table 2. Radon concentrations and the meteorological parameters during the period of observation at Mat Bridge and Tuichang. 


\begin{tabular}{|c|c|c|c|c|c|c|}
\hline \multirow[t]{2}{*}{ Model } & \multirow[t]{2}{*}{ Parameters } & \multicolumn{2}{|c|}{ Unstandardized coefficients } & \multirow{2}{*}{$\begin{array}{c}\text { Standardized } \\
\text { coefficients Beta }\end{array}$} & \multirow[t]{2}{*}{$\mathrm{t}$} & \multirow[t]{2}{*}{ Sig. (p- value) } \\
\hline & & B & Std. error & & & \\
\hline \multirow[t]{5}{*}{1} & (Constant) & 15506.483 & 12574.905 & & 1.233 & .225 \\
\hline & $R F$ & -1.069 & .513 & -.538 & -2.086 & .043 \\
\hline & RH & 11.267 & 3.994 & .666 & 2.821 & .007 \\
\hline & $T$ & 4.115 & 13.222 & .054 & .311 & .757 \\
\hline & $P$ & -18.091 & 13.854 & -.309 & -1.306 & .199 \\
\hline \multirow[t]{4}{*}{2} & (Constant) & 17546.232 & 10612.758 & & 1.653 & .106 \\
\hline & $R F$ & -1.090 & .503 & -.549 & -2.169 & .036 \\
\hline & $R H$ & 11.414 & 3.922 & .675 & 2.910 & .006 \\
\hline & $P$ & -20.287 & 11.791 & -.346 & -1.721 & .093 \\
\hline \multirow[t]{3}{*}{3} & (Constant) & -707.813 & 284.934 & & -2.484 & .017 \\
\hline & $R F$ & -.708 & .461 & -.356 & -1.535 & .132 \\
\hline & $R H$ & 12.804 & 3.926 & .757 & 3.261 & .002 \\
\hline \multirow[t]{2}{*}{4} & (Constant) & -371.602 & 185.026 & & -2.008 & .051 \\
\hline & $R H$ & 7.865 & 2.283 & .465 & 3.445 & .001 \\
\hline
\end{tabular}

Table 3. Coefficients of the Backward regression output at Mat Bridge.

able. Clearly, $R H$ is a significant predictor (p-value $<0.05)$ of $R n_{1}$.

To check how much of the criterion variability is accounted for by the predictor and the viability of the model-as-a-whole we examine the squared multiple $\mathrm{R}$ value and a significant $\mathrm{F}$-ratio $(\mathrm{p}<0.05)$ respectively, which is reported in Table 4. In the model summary of Table 4, R-square and adjusted R-square is reported. The adjusted R-square is the measure of the shrinkage if we were to apply this model to another sample (in other words the amount of predictive loss that we would observe). The value of adjusted Rsquare in model 4 is 0.198 i.e. $19.8 \%$ of the variation in radon concentration is accounted by $R H$. By reducing the number of predictors from 4 to 1 the adjusted Rsquare dropped from 0.240 to 0.198 , a change of 0.042 (or a little over $4 \%$ ) which is good. We do not lose much R-square by dropping 3 of the 4 predictor variables. Also the standard error of estimates increase from 162.51 to 166.99 (only $2.68 \%$ increase) which is not much. To test the significance of the model-as-awhole an F-ratio ( $\mathrm{MS}_{\text {reg. }} / \mathrm{MS}_{\text {res. }}$ ) is calculated for each model and the probability of the computed F-ratio is displayed in sig. column of Table 4. If we compare all the models, F-ratio is largest in Model 4 showing better ratio of regression to noise. Reducing the number of predictors from 4 to 1 reduces the p-value of F-ratio from 0.004 to 0.001 indicating a more significant and a better model. The raw score regression equation for Model 4 can be written as

$$
R n_{1}^{\prime}=-371.60+7.865(R H)
$$

\begin{tabular}{|c|c|c|c|c|c|c|c|c|c|}
\hline & Model & $\begin{array}{l}\text { Sum of } \\
\text { squares }\end{array}$ & $\mathrm{df}$ & $\begin{array}{l}\text { Mean } \\
\text { square }\end{array}$ & F & Sig. & $\mathrm{R}$ square & $\begin{array}{l}\text { Adjusted } \\
\text { R square }\end{array}$ & $\begin{array}{l}\text { Std. error } \\
\text { of estimates }\end{array}$ \\
\hline \multirow[t]{3}{*}{1} & Regression & 473551.25 & 4 & 118387.81 & & & & & \\
\hline & Residual & 1056409.54 & 40 & 26410.23 & 4.48 & .004 & .310 & .240 & 162.512 \\
\hline & Total & 1529960.80 & 44 & & & & & & \\
\hline \multirow[t]{3}{*}{2} & Regression & 470993.53 & 3 & 156997.84 & & & & & \\
\hline & Residual & 1058967.27 & 41 & 25828.47 & 6.07 & .002 & .308 & .257 & 160.712 \\
\hline & Total & 1529960.80 & 44 & & & & & & \\
\hline \multirow[t]{3}{*}{3} & Regression & 394529.07 & 2 & 197264.53 & & & & & \\
\hline & Residual & 1135431.72 & 42 & 27034.089 & 7.29 & .002 & .258 & .223 & 164.420 \\
\hline & Total & 1529960.80 & 44 & & & & & & \\
\hline \multirow[t]{3}{*}{4} & Regression & 330863.50 & 1 & 330863.50 & & & & & \\
\hline & Residual & 1199097.29 & 43 & 27885.98 & 11.9 & .001 & .216 & .198 & 166.990 \\
\hline & Total & 1529960.80 & 44 & & & & & & \\
\hline
\end{tabular}

Table 4. Model summary and analysis of variance (Mat Bridge). 


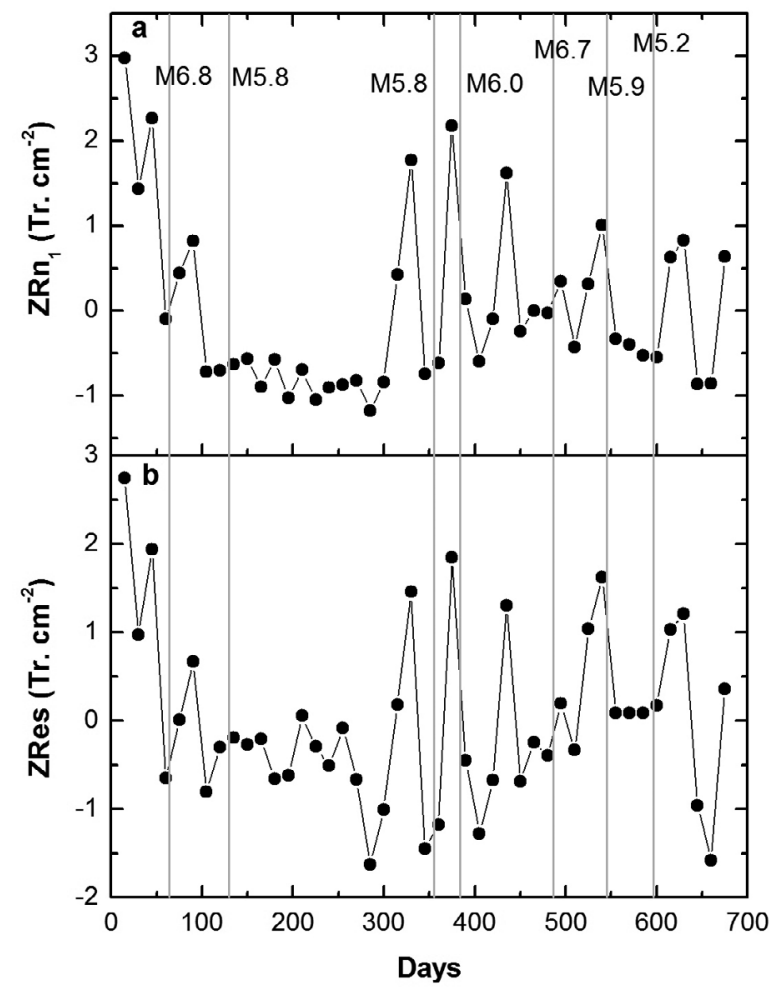

Figure 4. Variation of (a) Standardized measured radon concentration and (b) Standardized residuals during the observation period at Mat Bridge. The solid vertical lines represent the earthquakes along with their magnitudes $(\mathrm{M})$.

and the corresponding standardized equation would be

$$
Z R n_{1}^{\prime}=0.465(Z R H)
$$

where $Z R n^{\prime}{ }_{1}$ is the standardized value (Z-score) of $R n^{\prime}$ and $Z R H$ is the $Z$-score of $R H$. We calculate the $Z$ scores of the measured radon concentration $\left(Z R n_{1}\right)$ and relative humidity $(Z R H)$ during the entire period of observation and uses Equation (5) to find the standardized predicted value $\left(Z R n^{\prime}\right)$. When the difference (i.e. the standardized residuals) between $Z R n_{1}$ and $Z R n^{\prime}{ }_{1}$ is more than $1 \mathrm{SD}$, we denote it as a possible radon anomaly. The graphical representation of the standardized measured radon concentration and residuals during the observation period is shown in Figure 4.

The radon maximum observed on 45th day of the observation period (Figure 4a) was $Z R n_{1}=2.263$ Tracks $/ \mathrm{cm}^{2}$. The difference (ZRes.) between the measured and the predicted value was, $1.943 \mathrm{Tracks} / \mathrm{cm}^{2}$ (close to 2SD; Figure 4b). This radon maximum could be correlated to the earthquake of M6.8 which occurred on 65 th day of the observation period (i.e. 20 days after the anomaly was observed). The second radon peak was observed on 330th day. The difference between the measured and the predicted value was recorded to be ZRes. $=1.458 \mathrm{Tracks} / \mathrm{cm}^{2}$, which is greater than $1 \mathrm{SD}$. The second peak may be correlated to the earthquake of M5.8 which occurred on 353rd day (23 days after the anomaly was observed). The third anomalous change in radon concentration was recorded on 375th day. The difference between the measured and the predicted value during this period was recorded to be $1.847 \mathrm{Tracks} / \mathrm{cm}^{2}$ (much greater than 1SD). An earthquake of M6.0 occurred only 6 days after the anomaly was observed. So, the third radon maximum may be correlated to the mentioned M6.0 quake. The fourth maximum was recorded on 435th day. The difference in the concentration was recorded to be $1.305 \mathrm{Tracks} / \mathrm{cm}^{2}$ (just above $1 \mathrm{SD}$ level). Though an earthquake of M6.7 occurred several days after the anomaly was observed, it was quite difficult to directly correlate the radon maximum to the mentioned event as the time interval between the anomaly observed and the event was quite large (51 days). In other words, this radon maximum may be treated as a false anomaly

\begin{tabular}{|c|c|c|c|c|c|c|}
\hline \multirow[t]{2}{*}{ Model } & \multirow[t]{2}{*}{ Parameters } & \multicolumn{2}{|c|}{ Unstandardized coefficients } & \multirow{2}{*}{$\begin{array}{c}\text { Standardized } \\
\text { coefficients Beta }\end{array}$} & \multirow[t]{2}{*}{$\mathrm{t}$} & \multirow[t]{2}{*}{ Sig. (p-value) } \\
\hline & & B & Std. error & & & \\
\hline \multirow[t]{5}{*}{1} & (Constant) & 7180.246 & 10796.340 & & .665 & .510 \\
\hline & $R F$ & -1.212 & .440 & -.753 & -2.755 & .009 \\
\hline & RH & 10.783 & 3.429 & .787 & 3.145 & .003 \\
\hline & $T$ & -3.601 & 11.351 & -.059 & -.317 & .753 \\
\hline & $P$ & -8.577 & 11.894 & -.180 & -.721 & .475 \\
\hline \multirow[t]{4}{*}{2} & (Constant) & 5395.113 & 9112.143 & & .592 & .557 \\
\hline & $R F$ & -1.194 & .431 & -.742 & -2.767 & .008 \\
\hline & $R H$ & 10.654 & 3.367 & .777 & 3.164 & .003 \\
\hline & $P$ & -6.656 & 10.123 & -.140 & -.657 & .515 \\
\hline \multirow[t]{3}{*}{3} & (Constant) & -593.630 & 237.506 & & -2.499 & .016 \\
\hline & $R F$ & -1.069 & .384 & -.664 & -2.780 & .008 \\
\hline & $R H$ & 11.110 & 3.273 & .810 & 3.395 & .002 \\
\hline
\end{tabular}

Table 5. Coefficients of the Backward regression output at Tuichang. 


\begin{tabular}{|c|c|c|c|c|c|c|c|c|c|}
\hline & Model & $\begin{array}{l}\text { Sum of } \\
\text { squares }\end{array}$ & $\mathrm{df}$ & $\begin{array}{l}\text { Mean } \\
\text { square }\end{array}$ & $\mathrm{F}$ & Sig. & R square & $\begin{array}{l}\text { Adjusted } \\
\mathrm{R} \text { square }\end{array}$ & $\begin{array}{l}\text { Std. error } \\
\text { of estimates }\end{array}$ \\
\hline \multirow[t]{3}{*}{1} & Regression & 226690.92 & 4 & 56672.73 & & & & & \\
\hline & Residual & 778710.32 & 40 & 19467.75 & 2.91 & .033 & .225 & .148 & 139.526 \\
\hline & Total & 1005401.24 & 44 & & & & & & \\
\hline \multirow[t]{3}{*}{2} & Regression & 224731.88 & 3 & 74910.62 & & & & & \\
\hline & Residual & 780669.35 & 41 & 19040.71 & 3.93 & .015 & .224 & .167 & 137.988 \\
\hline & Total & 1005401.24 & 44 & & & & & & \\
\hline \multirow[t]{3}{*}{3} & Regression & 216501.64 & 2 & 108250.82 & & & & & \\
\hline & Residual & 788899.60 & 42 & 18783.32 & 5.76 & .006 & .215 & .178 & 137.052 \\
\hline & Total & 1005401.24 & 44 & & & & & & \\
\hline
\end{tabular}

Table 6. Model summary and analysis of variance (Tuichang).

which may have occurred due to variation in relative humidity. For the radon maximum that occurred on 540th day, the residual was 1.620 Tracks $/ \mathrm{cm}^{2}$ which is well above the $1 \mathrm{SD}$ level. This may be treated as a precursory signal before the event of M5.9 which occurred on 545 th day ( 5 days after the anomaly was observed).

\section{Data analysis at Tuichang}

As in case of Mat Bridge we perform backward regression taking $R n_{2}$ (measured radon concentration at Tuichang) as dependent variable and $R F, R H, T$ and $P$ as independent variables (data taken from Table 2). The SPSS print out of the results (coefficients) is shown in Table 5. The output of the backward regression method produces three models namely Model 1, Model 2 and Model 3. Model 1 includes all the predictor variables. Temperature $(\mathrm{T})$ is having a p-value of 0.753 which is greater than the $\alpha$-value (0.05); therefore T is removed from Model 1 to construct Model 2 with $R F, R H$ and $P$ as independent variables. It is clear from the sig. column of Table 5 that $P$ is a non-significant predictor (since the $\mathrm{p}$ value $>0.05$ ). Consequently, $P$ is removed from the Model and a third Model is established with two predictor variables $(R F$ and $R H)$. Both $R F$ and $R H$ are significant predictors since the $\mathrm{p}$-value in both the cases is less than 0.05 . The model summary and the analysis of variance are given in Table 6 . To verify the significance of the model-as-a-whole, first we look at the adjusted Rsquare value. The adjusted R-square value is 0.178 (i.e. $17.8 \%$ of the variation in radon concentration is explained by $R F$ and $R H$ ). Reducing the number of parameters from 4 to 2 does not reduce the adjusted R-square value. In fact, the value increases from 0.148 to 0.178 (i.e. $16.86 \%$ increase). Second, there is no increment in standard error of estimates by reducing the predictor variables which is a good indication that Model 3 is better. Third, the F-ratio is largest in Model 3 (i.e. a better ratio of regression to noise) and the p-value of F-ratio is least. In conclusion Model 3 is the most significant and a bet- ter model. The raw score and the Z-score regression equations for Model 3 can be written as

$$
\begin{aligned}
R n_{2}^{\prime} & =-593.63-1.069(R F)+11.110(R H) \\
Z R n_{2}^{\prime} & =-0.664(Z R F)+0.810(Z R H)
\end{aligned}
$$

where $Z R n_{2}^{\prime}, Z R F$ and $Z R H$ are the standardized value of $R n_{2}^{\prime}, R F$ and $R H$ respectively in units shown in Table 2.

The plot of standardized measured radon concentration and residuals during the observation period at Tuichang is shown in Figure 5. The first radon maximum was recorded on 90th day of the observation period (Figure 5a). During this period the difference between the

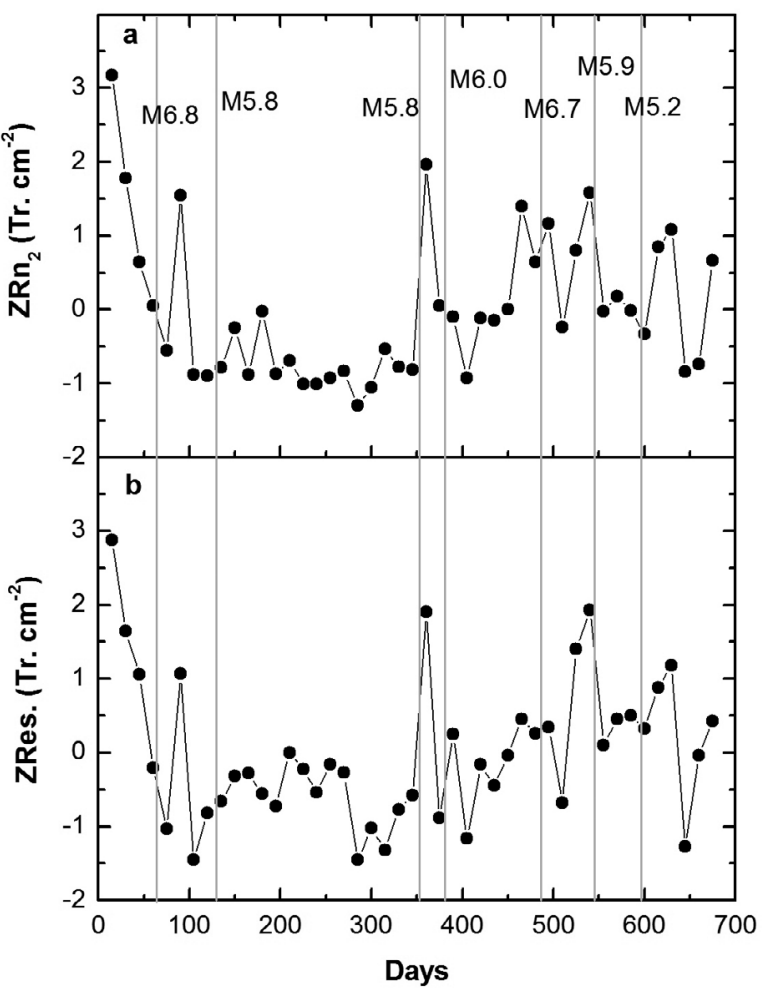

Figure 5. Variation of (a) Standardized measured radon concentration and (b) Standardized residuals during the observation period at Tuichang. The solid vertical lines represent the earthquakes along with their magnitudes $(\mathrm{M})$. 
measured and the predicted value of radon concentration was, ZRes. $=1.066 \mathrm{Tracks} / \mathrm{cm}^{2}$ (just above 1SD; Figure $5 \mathrm{~b}$ ). This radon maximum was quite difficult to directly correlate to any seismic event (as the time interval between the radon maximum and the closest earthquake M5.8 was 39 days). So, the first radon maximum may be treated as a false anomaly possibly may have caused by variation in meteorological parameters $(R F$ and $R H)$. The next increment in radon concentration was recorded on 360th day. The difference between the measured and the predicted value was recorded to be 1.902 Tracks $/ \mathrm{cm}^{2}$ (close to $2 \mathrm{SD}$ ). This peak may be correlated to the event of M6.0 which occurred 21 days after the anomaly was observed. Third change in radon concentration was observed on 495th day. But it was quite difficult to correlate this peak to the event of M6.7 as during this period the difference between the measured and the predicted value was quite low (ZRes. $=0.338$ Tracks $/ \mathrm{cm}^{2}$; less than 1SD). Next impulsive change was recorded on 540th day of the observation period. The difference between the measured and predicted value during this period was $1.934 \mathrm{Tracks} / \mathrm{cm}^{2}$ (close to $2 \mathrm{SD}$ ). The mentioned peak may be treated as a precursor signal before the earthquake of M5.9 which occurred 5 days after the signal.

\section{Conclusion}

We have performed statistical analysis of the radon data collected from July 2011 to May 2013 at two sites (Mat bridge and Tuichang) along Mat Fault, the most prominent fault in Mizoram. The multiple regression analysis of the radon data with the meteorological parameters provides useful evidence to extract a radon anomaly possibly caused by seismic event. The results obtained shows that at Mat Bridge about $57 \%$ of the anomaly observed could be correlated to the seismic events whereas at Tuichang $28.6 \%$ could be correlated, indicating that the radon activity in soil gas is mostly controlled by geophysical process. The precursor time between the observed radon anomalies and the earthquakes varies from 5-23 days. High percentage of correlation between radon anomalies and the earthquakes at Mat Bridge indicates that the area under investigation is seismically active and would be useful to carry out further studies. Several spike-like radon anomalies observed prior to the earthquakes in the present investigation may provide soil radon database and the preliminary trend of their response to earthquake activity in the region. The Backward regression method applied gives valuable information about the meteorological parameter(s) that have the strongest effect on radon concentration. However, long term and continuous data recording is necessary to confirm a relation between soil radon activity and earthquakes.
Acknowledgements. Authors are grateful to the Ministry of Earth Sciences, Govt. of India, New Delhi for their financial support to this work in the form of a Major project vide Sanction order No. MoES/ P.O.(Seismo) / 1(67)/2009, Dated 16-06-2010.

\section{Data and sharing resources}

The earthquake catalog used in this study was obtained from:

http:/ /www.imd.gov.in/section/seismo/dynamic/wel come.htm

\section{References}

Choubey, V.M., N. Kumar and B.R. Arora (2009). Precursory signatures in the radon and geohydrological borehole data for M4.9 Kharsali earthquake of Gharwal Himalaya, Sci. Tot. Environ., 407, 58775883.

Dewey, J.F., and J.M. Bird (1970). Mountain belts and the new global tectonics, J. Geophys. Res., 75, 26252647.

Fleischer, R.L. (1981). Dislocation model for radon response to distant earthquakes, Geophys. Res. Lett., 84, 77-480.

Fu, C.C., T.F. Yang, V. Walia and C.H. Cheng (2005). Reconnaissance of soil gas composition over the buried fault and fracture zone in Southern Taiwan, Geochem. J., 39, 427-439.

Hocking, R.R. (1976). The analysis and selection of variables in Linear regression, Biometrics, 32, 1-49.

Jaishi, H.P., S. Singh, R.P. Tiwari and R.C. Tiwari (2013). Radon and thoron anomalies along Mat fault in Mizoram, India, J. Earth Syst. Sci., 122, 1507-1513.

Jaishi, H.P., S. Singh, R.P. Tiwari and R.C. Tiwari (2014a). Correlation of radon anomalies with seismic events along Mat fault in Serchhip District, Mizoram, India, Appl. Radiat. Isot., 86, 79-84.

Jaishi, H.P., S. Singh, R.P. Tiwari and R.C. Tiwari (2014b). Temporal variation of soil radon and thoron concentrations in Mizoram (India), associated with earthquakes, Nat. Hazards, 72, 443-454.

King, C.Y. (1986). Gas Geo Chemistry Applied to Earthquake Prediction: An Overview, J. Geophys. Res., 91, 12269-12281.

King, C.Y., and A. Minissale (1994). Seasonal variability of soil-gas radon concentration in central California, Radiat. Meas., 23, 683-692.

King, C.Y., B.S. King, W.C. Evans and W. Zhang (1996). Spatial radon anomalies on active faults in California, Appl. Geochem., 11, 497-510.

Kraner, H.W., G.L. Schroeder and R.D. Evans (1964). Measurements of the effects of atmospheric variables on radon-222 flux and soil gas concentration, In: J.A.S and W.M. Adams (eds.), The Natural Radiation and Environment, Symposium Proceedings 
(Houston, Texas, April 10-13, 1963), Lower, Univ. Chicago Press, Chicago, 191-215.

Pearson, J.E. (1967). Natural Environmental Radioactivity from Radon-222, In: U.S Public Health Service Publication No. 999-RH-26, U.S. Dept. of Health, Education and Welfare, Washinton, D.C., 31 pp.

Price, J.G., J.G. Rigby, L. Christensen, R. Hess, D.D. LaPointe, A.R. Ramelli, M. Desilets, R.D. Hopper, T. Kluesner and S. Marshall (1994). Radon in outdoor in Nevada, Health Physics, 66, 433-438.

Raghukanth, S.T.G., and S.K. Dash (2009). Deterministic seismic scenarios for North East India, J. Seismol., 14, 143-167.

Ramola, R.C., Y. Prasad, G. Prasad, S. Kumar and V.M. Choubey (2008) Soil-gas radon as seismotectonic indicator in Garhwal Himalaya, Appl. Radiat. Isot., 66, 1523-1530.

Rannou, A. (1990). The bare detector and results of indoor radon Survey in France, In: Proceedings of the International Workshop on Radon monitoring in Radioprotection, Environmental Radioactivity and Earth Sciences (ICTP, Trieste, Italy, April 3-14, 1989), World Scientific publication, 145-222.

Singh, M., R.C. Ramola, N.P. Singh, S. Singh and H.S. Virk (1988). Influence of meterological parameters on soil gas radon, J. Assoc. Explor. Geophys., 9, 85-90.

Singh, S., H.P. Jaishi, R.P. Tiwari and R.C. Tiwari (2014). Variations of soil radon concentrations along Chite Fault in Aizawl district, Mizoram, India, Radiat. Prot. Dosim.; doi:10.1093/rpd/ncu221.

Virk, H.S., V. Walia, A.K. Sharma, N. Kumar and R. Kumar (2000). Correlation of radon anomalies with microseismic events in Kangra and Chamba valleys of N-W Himalaya, Geofis. Int., 39, 221-227.

Walia, V., H.S. Virk, T.F. Yang, S. Mahajan, M. Walia and B.S. Bajwa (2005). Earthquake Prediction Studies Using Radon as a Precursor in N-W Himalayas, India: A Case Study, TAO, 16, 775-804.

Yount, W.R. (2006). Research Design and Statistical analysis in Christian Ministry, 4th Edition, Forth Worth, Texas: Southwest Baptist Theological Seminary, 26.1-26.12.

Zmazek, B., L. Todorovski, S. Dmeroski, J. Vaupotic and I. Kobal (2003). Application of decision trees to the analysis of soil radon data for earthquake prediction, Appl. Radiat. Isot., 58, 697-706.

${ }^{\star}$ Corresponding author: Ramesh Chandra Tiwari,

Mizoram University, Department of Physics, Aizawl, India;

email: ramesh_mzu@rediffmail.com.

(C) 2014 by the Istituto Nazionale di Geofisica e Vulcanologia. All

rights reserved. 